\title{
Cardiovascular magnetic resonance characterisation of pericardial and myocardial involvement in patients with tuberculous pericardial constriction with and without HIV co-infection
}

\author{
Ntobeko A Ntusi ${ }^{1}$, Gregori Palkowski ${ }^{1}$, Petronella Samuels ${ }^{2}$, Sulaiman Moosa ${ }^{3}$, Mpiko Ntsekhe ${ }^{1}$, Bongani Mayosi ${ }^{1}$ \\ From 19th Annual SCMR Scientific Sessions \\ Los Angeles, CA, USA. 27-30 January 2016
}

\section{Background}

Tuberculosis pericarditis (TBP) is the most common cause of a large pericardial effusion in the developing world, accounting for $70 \%$ of effusions in a case series from South Africa; and has a high mortality related to pericardial tamponade, constrictive pericarditis, arrhythmias and heart failure. Manifestations of TBP include pericarditis with pericardial effusion, effusive-constrictive and constrictive pericarditis. There has been a dramatic resurgence in TBP in the context of co-infection with the human immunodeficiency virus (HIV). Almost 100\% of pericardial effusions in those infected with HIV in sub-Saharan Africa are due to tuberculosis, compared with $50-70 \%$ in those HIV-uninfected and less than 5\% in industrial nations. In patients with TBP, co-infection with HIV is associated with increased heart failure, haemodynamic instability, electrocardiographic (ECG) ST elevation and mortality, suggesting an aggressive myopericarditis in the context of HIV co-infection. However, little is known about myocardial involvement in patients with TBP. Cardiovascular magnetic resonance (CMR) can assess non-invasively cardiac function, myocardial oedema, inflammation and fibrosis. We hypothesised that HIV co-infection would be associated with increased myocardial pathology on CMR in patients with TBP.

\section{Methods}

The purpose of this study was to assess cardiac and pericardial structure and function in patients with TBP

'Division of Cardiology, Department of Medicine, University of Cape Town \& Groote Schuur Hospital, Cape Town, South Africa

Full list of author information is available at the end of the article with and without HIV co-infection and to assess the relationship of LV function with other imaging biomarkers. 72 patients with TBP (37 male (51.3\%), mean age $40 \pm 14.3)$ were included in the study. Of these, 35 were HIV-infected (17 male (48.6\%), mean age $34 \pm 8$ ) and 37 were HIV-uninfected (20 male (54.1\%), mean age $51 \pm 16$ ). Assessments included clinical examination, ECG, echocardiography, serum and pericardial biomarkers and CMR (biventricular volumes and function, oedema, and late gadolinium enhancement - LGE).

\section{Results}

HIV-infected TBP patients were younger $(\mathrm{p}<0.001)$, had lower serum haemoglobin $(\mathrm{p}<0.001)$ and were more likely to have NYHA class III and IV symptoms $(\mathrm{p}<0.001)$. There were no differences on ECG and echocardiography between HIV-infected and -uninfected TBP patients. There were also no differences in global systolic function and myocardial signal intensity ratio on STIR imaging between HIV-infected and -uninfected TBP patients. Focal fibrosis on LGE was found more commonly in those with HIV infection $(\mathrm{p}<0.001)$. Pericardial effusions were frequent $(>50 \%)$ in both groups of TBP patients. Determinants of LV ejection fraction in TBP included heart rate, LV size, E/A ratio, pericardial LGE and pericardial thickness (all $\mathrm{p}<0,01$ ).

\section{Conclusions}

HIV co-infection is associated with increased focal myocardial fibrosis in TBP patients suggesting increased myocardial inflammation in those with HIV co-infection. In the future, it will be important to assess the prognostic significance of these data. 


\section{Authors' details}

'Division of Cardiology, Department of Medicine, University of Cape Town \& Groote Schuur Hospital, Cape Town, South Africa. ${ }^{2}$ Cape Universities Body Imaging Centre, University of Cape Town, Cape Town, South Africa.

${ }^{3}$ Department of Radiology, 2 Military Hospital, Cape Town, South Africa.

Published: 27 January 2016

doi:10.1186/1532-429X-18-S1-Q29

Cite this article as: Ntusi et al:: Cardiovascular magnetic resonance characterisation of pericardial and myocardial involvement in patients with tuberculous pericardial constriction with and without HIV co-infection. Journal of Cardiovascular Magnetic Resonance 2016 18(Suppl 1):Q29.

Submit your next manuscript to BioMed Central and take full advantage of:

- Convenient online submission

- Thorough peer review

- No space constraints or color figure charges

- Immediate publication on acceptance

- Inclusion in PubMed, CAS, Scopus and Google Scholar

- Research which is freely available for redistribution

Submit your manuscript at www.biomedcentral.com/submit 